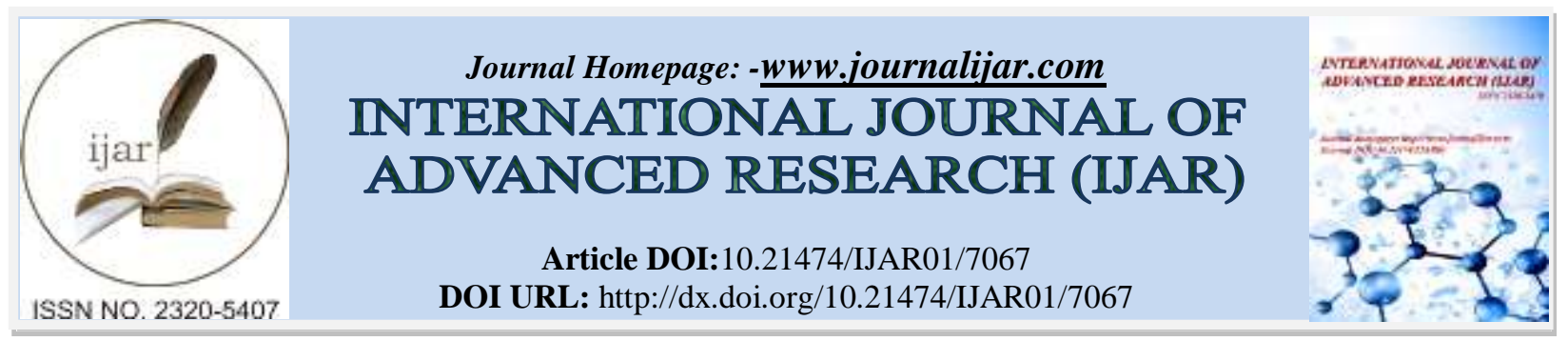

RESEARCH ARTICLE

"FOR ALL THE HAPPINESS MANKIND CAN GAIN, IS NOT IN PLEASURE BUT IN REST FROM PAIN."

L. Kalaivani.

Manuscript Info

Abstract

Manuscript History

Received: 10 March 2018

Final Accepted: 12 April 2018

Published: May 2018

Copy Right, IJAR, 2018,. All rights reserved.

\title{
Introduction:-
}

Pain is the most frequent symptoms which leads a person to seek medical help. The communication of a person's painful experience to health care professionals assists the person by understanding the conditions and providing therapeutic measures. Experiencing painful stimuli can lead to physical tensions that result in disturbed sleep pattern.

Birthing is the most profound initiation to spirituality a women can have. Birth of a baby is an event of celebration and mother remember no more than, for joy that a baby is born into the world.

Dr.Edmund Jacobson's progressive muscle relaxation exercise involves relaxing and tensing various muscle groups, which leads to reduced stress and muscle tension. He also found that the relaxation procedure is effective against reducing pain, ulcers, insomnia, and hypertension.

The goal of this progressive muscle relaxation exercise is to get to know the differences between how your muscles feel when they are tensed and when they are relaxed, so you can tell when you are tensed during the day and use it as a means to relax. The rate of caesarian section is $31 \%$ in our country. The postnatal mother after caesarian section experiences increased pain and sleep disturbances. Hence there is increased need felt for the study.

\section{Statement Of The Problem:-}

A Study to assess the effectiveness of Jacobson's Relaxation Technique on reduction of pain and sleep disturbances in mothers after caesarian section, at selected hospitals, Coimbatore.

\section{Objectives:-}

1. To assess the pain level of the mother post operatively.

2. To assess the sleep pattern disturbances of the mother post operatively.

3. To provide teaching regarding Jacobson's Relaxation technique.

4. To assess the effectiveness of planned Jacobson's relaxation technique on reduction pain.

5. To assess the effectiveness of planned Jacobson's relaxation technique on sleep pattern disturbances.

6. To associate the selected demographic variables with reduction of pain and improvement of sleep pattern after caesarian section. 


\section{Methodology:-}

Experimental approach, a subtype of quantitative approach was used for the present study. 60 postnatal mothers who had undergone caesarian section at selected hospitals in Coimbatore were selected for this study by using purposive sampling technique.

The researcher has developed an interview schedule to measure the effectiveness's of Jacobson's relaxation technique on reduction of pain and sleep pattern disturbances after caesarian section which consists of the following sections:

1. Distribution of demographic variable.

2. Numerical pain rating scale to measure the severity of pain.

3. Questions regarding sleep pattern disturbances which consists of 4 options and includes 17 symptoms.

\section{Results:-}

This present study was undertaken to assist the effectiveness of Jacobson's Relaxation technique on reduction of pain and sleep pattern disturbances after caesarian section among mothers at selected hospitals Coimbatore.

The data is organized, analyzed by using descriptive and inferential statistics and presented as follows:

1. Mean score of pain was 6.84 in pretest and it has been reduced to 1.04 in post test.

2. The mean score of sleep pattern disturbances in pretest was 40.56. and 33.44 in post test

3. The obtained " $\mathrm{t}$ " value for pain was 15.4 and sleep disturbances was 15.41 at 24 degrees of freedom and $0.05 \%$ level of significance which is higher than the table value which implies that there is a significant difference between the pain and sleep pattern disturbance after education regarding Jacobson's Relaxation Technique.

4. There is no significant association of pain and sleep pattern score with selected demographic variables of postnatal mothers.

\section{Conclusion:-}

The educative measures show that there was a significant reduction of pain and sleep pattern disturbances among postnatal mothers after practicing Jacobson's Relaxation technique.

\section{Recommendation:-}

1. A similar study can be replicated on a larger population with different age group

2. Intervention study can be undertaken to know the effect of Jacobson's relaxation technique on stress and anxiety of mothers in antenatal ward.

\section{Bibliography:-}

1. Adele pilliteri(1999), maternal and child health nursing ( $3^{\text {rd }}$ edition). New York Lippincott Publication.

2. Bennetv. Ruth Myles (1998), Text book for midwives ( $18^{\text {th }}$ edition). London Edinburg compang.

3. Anuchitra, S. (2004), Effect of relaxation on insomnia. Health action. 21, $12-15$.

4. Anit, M and Harsh. P( 2009), Caesarean section, a national survey . Obstetrics and Gyanecology of India. 59 (2). 